\title{
In-Hospital Costs Associated with New Percutaneous Coronary Devices
}

\author{
Ronald J. Dick, MBBS, Jeffrey J. Popma, MD, David W.M. Muller, MBBS, \\ Karen A. Burek, RN, and Eric J. Topol, MD
}

\begin{abstract}
To determine the relative economlc Impact of alternative methods of coronary revascularization, in-hospital patient accounts were reviewed in
\end{abstract} 149 patients undergoing elective coronary angioplasty $(n=50)$, coronary atherectomy $(n=72)$ or intracoronary stent placement $(n=27)$ over an 18-month period. Clinical and angiographic features were similar in the 3 groups, except that prior restenosis was seen more often in patients undergoing intracoronary stent placement. Procedural success, obtained in $>\mathbf{9 0} \%$ of patients, was independent of the treatment strategy. Total in-hospital stay was significantly longer in patients undergoing intracoronary stent placement than in patients undergoing coronary angioplasty and directional atherectomy (4.9 \pm 2.4 days vs $1.5 \pm 1.3$ and $2.2 \pm 3.9$ days, respectively; $p<0.0001$ ). Furthermore, the total in-hospital charges were significantly higher in patients undergoing intracoronary stent placement $\mathbf{( \$ 1 2 , 5 7 4} \pm \$ 4,564$ vs $\$ 6,220 \pm \$ 5,716$; p <0.001) and directional atherectomy $(\$ 8,329$ $\pm \$ 8,588$ vs $\$ 6,220 \pm \$ 5,716 ; p<0.01$ ) than in patients undergoing coronary angioplasty, reflecting overall differences in room costs, laboratory fees and pharmacy fees. The longer in-hospital stay in the intracoronary stent group was primarily attributed to the time required for anticoagulation with coumadin. It is concluded that a 102 and $34 \%$ increase in early hospltal charges resulted with stenting or directional atherectomy, respectively, compared with coronary angioplasty. These increased in-hospital charges were chiefiy due to the prolonged hospitalization time, device cost, laboratory fees and, in patients with intracoronary stents, the prolonged time needed to achieve systemic anticoagulation.

(Am J Cardiol 1991;68:879-885)

From the Department of Internal Medicine (Cardiology Division), University of Michigan Medical Center, Ann Arbor, Michigan. Manuscript received March 28, 1991; revised manuscript received May 28, 1991, and accepted May 30.

Address for reprints: Eric J. Topol, MD, Cardiac Catheterization I aboratory, B1-F245, University of Michigan Medical Center, Ann Arbor, Michigan 48109-0022. ince its introduction in $1977,{ }^{1} 2$ major limitations have been noted after coronary angioplasty. First, despite pretreatment with antiplatelet agents and heparin, abrupt vessel closure develops in 4 to $7 \%$ of cases within 24 hours of the procedure. ${ }^{2,3}$ Second, delaycd restenosis, often requiring a repeat revascularization procedure, develops in 30 to $40 \%$ of patients within the subsequent 3 to 6 months. ${ }^{4}$ As a result of these shortcomings, alternative mechanical techniques such as intracoronary stenting, ${ }^{5-7}$ atherectomy, ${ }^{8,9}$ and laser angioplasty ${ }^{10}$ have been advocated.

Whereas initial investigation using these new devices has focused on defining safety and clinical efficacy, little attention has been focused on the economic impact of these new technologies. Prior retrospective series have suggested that coronary angioplasty may be less costly than bypass surgery, ${ }^{11-15}$ but no previous study has compared the incremental costs of the use of alternative mechanical devices with standard coronary angioplasty. Therefore, we analyzed in-hospital charges from 149 patients undergoing coronary angioplasty, coronary atherectomy or intracoronary stenting procedures.

\section{METHODS}

Patient population: From January 1, 1989, to June $30,1990,1,014$ coronary interventions (coronary angioplasty, 858; directional coronary atherectomy, 116; intracoronary stent, 40 ) were performed at the University of Michigan Medical Center. For the purposes of this analysis, only patients with New York Heart Association class II to III angina undergoing elective coronary revascularization, admitted specifically for the procedure, were selected for the study. To avoid potential bias or imbalance of acuity of illness, palients with acute myocardial infarction, cardiogenic shock or unstable angina werc excluded from the analysis. Patients were not excluded with multivessel disease, abnormal left ventricular function, or complex lesion morphology according to American College of Cardiology/American Heart Association guidelines. ${ }^{16}$ An intention-totreat principle was adapted with inclusion of patient data irrespective of the success of the revascularization procedure.

CORONARY ANGIOPLASTY: Random selection of 50 patients undergoing coronary angioplasty was performed 
by reviewing every twelfth case record of the 858 angioplasty cases attempted during the study period. Unless contraindicated, all patients were pretreated with aspirin. After administration of a 10,000-unit bolus of heparin, coronary angioplasty was performed using standard methods. ${ }^{1,2}$ Additional heparin was administered hourly and, in the presence of thrombus or dissection, a heparin infusion was continued for an additional 12 to 24 hours, maintaining the partial thromboplastin time 1.5 to 2.5 times control. Patients who developed hemodynamic instability or prolonged myocardial ischemia were admitted to an intensive care unit; patients without complications were admitted to a specialized care unit for observation. Generally, 8Fr sheaths were used for coronary angioplasty and 8 hours of bedrest were prescribed after sheath removal.

DIRECTIONAL CORONARY ATHERECTOMY: Of the 112 patients undergoing coronary atherectomy using the Simpson AtheroCath ${ }^{\mathrm{TM}}$ (Devices for Vascular Intervention, Redwood City, California) during the study period, 40 were excluded because of unstable symptoms requiring hospitalization before atherectomy $(n=37)$ or because audited accounts were unavailable for review $(n=3)$. The remaining 72 patients were included in the analysis. After premedication as for patients undergoing coronary angioplasty, coronary atherectomy was performed using an $11 \mathrm{Fr}$ sheath by the method previously described. ${ }^{17}$ After atherectomy, in the absence of ischemic complications or coronary dissection, patients were admitted to a specialized care unit for observation. In general, 11 hours of bedrest were prescribed after sheath removal.

INTRACORONARY STENT PLACEMENT: Of the 40 patients undergoing stent implantation during the study period, 13 were excluded owing to unstable symptoms requiring hospitalization at the time of intracoronary stent placement $(n=11)$ or because audited accounts were unavailable for review $(n=2)$. The 27 remaining patients composed the study group. In addition to aspirin and a calcium antagonist, all patients undergoing intracoronary stent placement were pretreated with dipyridamole and intravenous dextran beginning 4 hours before the procedure. After predilation using standard angioplasty methods, intracoronary stent placement (Palmaz-Schatz Stent, Johnson and Johnson Interventional Systems, Warren, New Jersey) was performed using previously described methods. ${ }^{5,18}$ After stent implantation, patients continued to receive intravenous heparin until adequate oral anticoagulation could be obtained with coumadin (prothrombin time 1.5 times control). A 9 to $11 \mathrm{Fr}$ sheath was used for stent placement and was removed within 12 hours after intracoronary stent placement. In the absence of bleeding at the periaccess site, 9 to 11 hours bedrest after sheath removal were recommended.

Procedural success and in-hospital complications:

Procedural success was defined as a final diameter stenosis $<50 \%$ and the absence of in-hospital ischemic complications, including coronary bypass surgery, myocardial infarction or abrupt closure. Significant bleeding complications were defined by a decrease in the hematocrit to $<25 \%$ or those requiring a blood transfusion. Hematomas were defined as a $>4 \mathrm{~cm} \times 4 \mathrm{~cm}$ collection of subcutaneous collection of blood at the periaccess site.

Analysis of procedural charges: After patient discharge, the audited in-hospital accounts of the 149 patients used in this analysis were reviewed; only patient expenditures directly related to the procedure performed were included. During the study period of 1989 to 1990 , the cost/charge ratio for all services at the University of Michigan Medical Center was 0.76 .

CARDIAC CATHETERIZATION CHARGES: Procedure duration (in hours) was used to estimate personnel and equipment allocation for each of the 3 methods of revascularization and a time-adjusted catheterization room charge was determined. Additional charges within the cardiac catheterization laboratory included charges for intravascular sheaths, guiding catheters and balloon dilatation catheters. Under the investigational protocols operational during the study period, expenditures for intracoronary stents and atherectomy devices were not applied to individual patient accounts, but were borne directly by the hospital. To estimate the total procedural costs, the hospital charges by the investigational device manufacturer were added individually to the cardiac catheterization charges. During the study period, per patient hospital charges were $\$ 1,095$ for the atherectomy equipment (atherectomy device, $\$ 850$; guiding catheter, $\$ 130$; motor drive unit, $\$ 90$; hemostatic valve, $\$ 25)$ and $\$ 1,000$ for each intracoronary stent. Professional fees for any procedure and charges for out-patient services were not included in the analysis.

PHARMACY CHARGES: During the hospitalization period, pharmacy charges covering intravenous fluids and medications including aspirin, a calcium antagonist and analgesics were tabulated for all patients. In patients with intracoronary stents, the charge for oral coumadin and dextran were also added.

LABORATORY CHARGES: Routine plasma chemistries and hematologic profiles were obtained in all patients before and after the procedure. Coagulation profiles including a thrombin clotting time and heparin units were obtained in patients who continued to receive intravenous heparin after the procedure and in patients 


\begin{tabular}{|llll|}
\hline \multicolumn{3}{|l|}{ TABLE I Clinical and Angiographic } & Features Before \\
Revascularization
\end{tabular}

undergoing intracoronary stent placement, until therapeutic oral anticoagulation was achieved. Remaining laboratory tests and any indication for blood transfusion was left to the discretion of the individual physicians caring for the patients.

ROOM CHARGES: In general, patients were admitted to a specialized care unit with continuous cardiac monitoring after the procedure. Daily hospital charges for this classification of hospital bed were $\$ 606$ to $\$ 656 /$ day. Patients with prolonged myocardial ischemia, hemodynamic compromise or other cardiac complications admitted to the intensive care unit were charged $\$ 1,545 /$ day.

INCIDENTAL CHARGES: All patients also received accounts for incidental charges. These charges included the charge for telemetry, respiratory care therapy equipment, extra lines required for intravenous therapy and use of infusion pumps.

Ambulatory status during hospitalization: To determine the relative patient dependency during hospitalization, medical records were reviewed to determine ambulatory status of patients during hospitalization. The following classification was used: (1) bedrestsheath in place - time from completion of the proce-

\begin{tabular}{|c|c|c|c|}
\hline Event & $\begin{array}{l}\text { Coronary } \\
\text { Angioplasty } \\
(n=50)\end{array}$ & $\begin{array}{l}\text { Directional } \\
\text { Atherectomy } \\
(\mathrm{n}=72)\end{array}$ & $\begin{array}{l}\text { Intracoronary } \\
\text { Stenting } \\
(n=27)\end{array}$ \\
\hline \multicolumn{4}{|l|}{ Procedural outcome } \\
\hline Primary success (\%) & $46(92)$ & $66(92)$ & $2(93)$ \\
\hline Primary failures (\%) & $3(6)$ & $5(7)$ & $25(7)$ \\
\hline Urgent CABG $(\%)$ & $1(2)$ & $1(1)$ & $0(0)$ \\
\hline \multicolumn{4}{|l|}{ In-hospital complications } \\
\hline Subacute closure (\%) & $1(2)$ & $0(0)$ & $1(4)$ \\
\hline Recath-chest pain (\%) & $0(0)$ & $0(0)$ & $5(19)$ \\
\hline \multicolumn{4}{|l|}{ Femoral artery } \\
\hline Bleed $(\%)$ & $O(0)$ & $0(0)$ & $4(15)^{\star}$ \\
\hline Hematoma $(\%)$ & $1(2)$ & $6(8)$ & $3(11)^{*}$ \\
\hline Vascular repair & $0(0)$ & $1(1)$ & $2(7)$ \\
\hline CNS complication (\%) & $0(0)$ & $1(1)$ & $0(0)$ \\
\hline
\end{tabular}

dure until the sheath removal; (2) bedrest-sheaths removed - period after the sheath removal until ambulation, and including any time required because of hematomas or femoral artery bleeding; and (3) ambulatory - time from ambulation until discharge, including the period of oral anticoagulation in patients undergoing intracoronary stent placement.

Statistical analysis: Continuous variables are expressed as mean \pm 1 standard deviation. Differences between continuous variables were analyzed using analysis of variance for multiple comparisons and differences in frequencies were analyzed using chi-square analysis. Nonparametric analysis was applied when appropriate. Differences at $p<0.05$ were considered significant.

\section{RESULTS}

Clinical characteristics, procedural outcome and inhospital complications: Clinical findings in patients undergoing coronary revascularization are listed in Table I. Procedural success obtained in $>90 \%$ of procedures did not vary significantly by treatment strategy (Table II). Repeat angiography for recurrent chest pain in patients undergoing intracoronary stent placement was performed for chest discomfort and any suggestive electrocardiographic changes of ischemia. In the 5 patients undergoing repeat coronary arteriography for recurrent chest pain in this group, abrupt closure was demonstrated in only 1 . Femoral artery rebleeding and hematoma formation were more frequent in patients undergoing intracoronary stent placement, although hematoma formation was not significantly different from patients undergoing directional atherectomy. Notably, patients undergoing intracoronary stent placement had 
significantly longer periods of bedrest-sheaths in place, bedrest-sheaths removed, and in-hospital ambulatory status than patients undergoing coronary angioplasty or directional atherectomy (Figure 1).

In-hospital charge analysis: Although the in-hospital stay was similar for patients undergoing coronary angioplasty and directional atherectomy, significantly longer hospital stays were required in patients undergoing intracoronary stent placement (Table III). This longer in-hospital period was associated with higher room charges, laboratory and pharmacy fees, and total hospital charges in the intracoronary stent group. Thus, the total in-hospital charges for intracoronary stent placement was slightly more than double that of standard coronary angioplasty and $>30 \%$ greater than di- rectional atherectomy $(p<0.001)$ (Figure 2). Directional coronary atherectomy was also associated with $34 \%$ higher hospital charges than coronary angioplasty.

\section{DISCUSSION}

Because of limitations of coronary angioplasty, including abrupt vessel closure ${ }^{2,3}$ and late restenosis, ${ }^{4}$ alternative methods of coronary revascularization have been investigated..$^{5-10}$ Despite encouraging angiographic and clinical results using these alternative techniques, ${ }^{19}$ little attention has been focused on the potential economic cost of their more widespread application. To define the relative resource allocation required by coronary angioplasty and 2 of these alternative methods, directional atherectomy and intracoronary stent-

\begin{tabular}{|c|c|c|c|}
\hline & $\begin{array}{l}\text { Coronary } \\
\text { Angioplasty } \\
(n=50)\end{array}$ & $\begin{array}{l}\text { Directional } \\
\text { Atherectomy } \\
(n=72)\end{array}$ & $\begin{array}{l}\text { Intracoronary } \\
\text { Stenting } \\
(n=27)\end{array}$ \\
\hline Hospital duration (days) & $1.5 \pm 1.3$ & $2.2 \pm 3.9$ & $4.9 \pm 2.4^{* \dagger}$ \\
\hline Cath laboratory charge & $4,044 \pm 974$ & $3,406 \pm 1,289$ & $5,518 \pm 1,546^{*} \dagger$ \\
\hline Device cost & Included & $1,260 \pm 386$ & $1,150 \pm 362$ \\
\hline Pharmacy charges & $158 \pm 231$ & $313 \pm 787$ & $454 \pm 287^{*} \dagger$ \\
\hline Laboratory charges & $290 \pm 470$ & $582 \pm 1,144^{*}$ & $989 \pm 805^{*} \uparrow$ \\
\hline Room charges & $964 \pm 1,019$ & $1,703 \pm 2,961$ & $3,376 \pm 2,308^{*} \dagger$ \\
\hline Miscellaneouls & $763 \pm 3,730$ & $1,066 \pm 4,032$ & $1,087 \pm 887$ \\
\hline Total charges $(\$)$ & $6,220 \pm 5,716$ & $8,329 \pm 8,588^{*}$ & $12,574 \pm 4,564^{*} \dagger$ \\
\hline $\begin{array}{l}\% \text { Increase over coronary } \\
\text { angioplasty }\end{array}$ & - & +34 & +103 \\
\hline
\end{tabular}

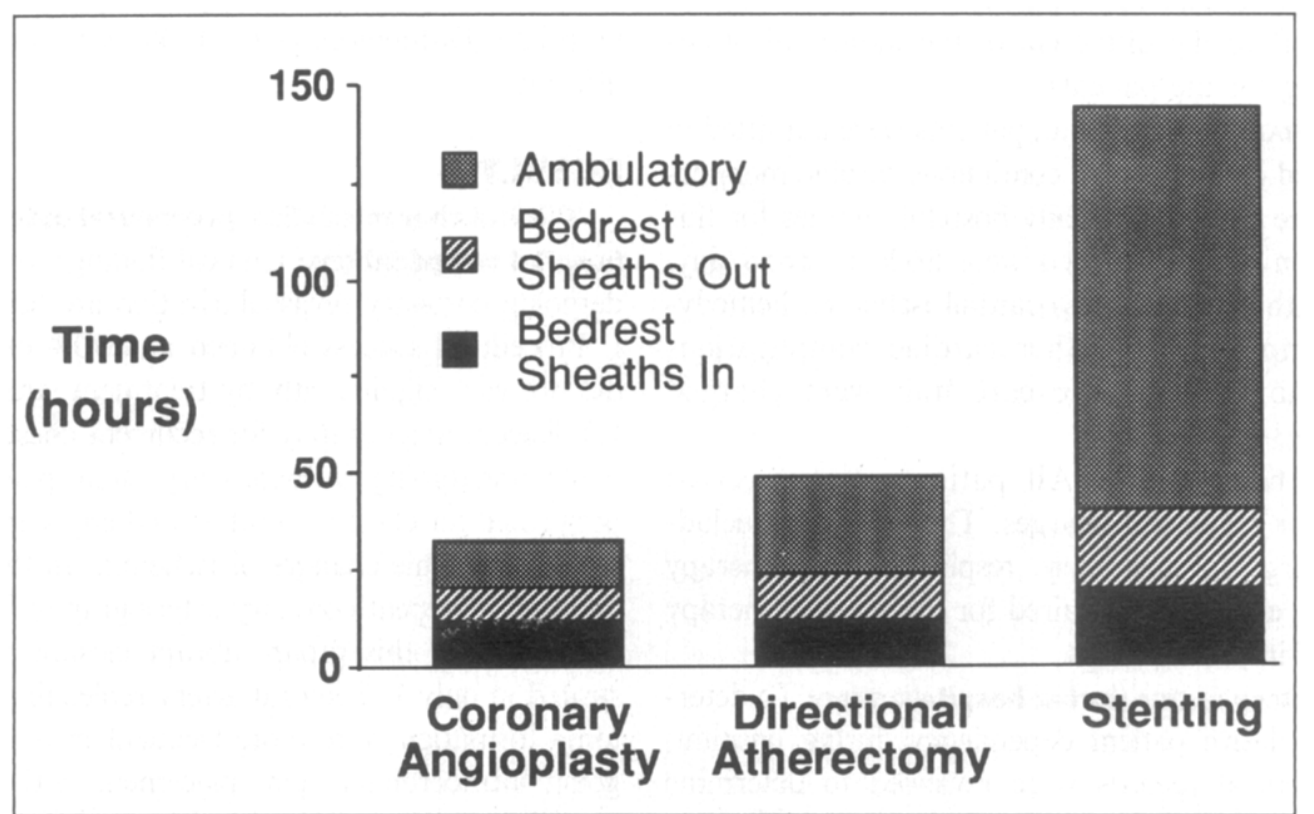

FIGURE 1. Ambulation status of patients undergoing nonsurgical coronary revascularization. Patients undergoing intracoronary stenting had significantly longer in-hospital stays, primarily reflected by longer periods of bedrest with sheaths out and ambulation before hospital discharge than coronary angioplasty or directional atherectomy. 
ing, the present study was performed by reviewing the in-hospital accounts of 149 patients undergoing elective revascularization using one of these techniques. Compared with patients undergoing coronary angioplasty, in-hospital charges were $102 \%$ higher in patients undergoing intracoronary stent placement and $34 \%$ higher in patients undergoing directional atherectomy. Significantly longer hospitalization periods required in patients undergoing stent placement accounted for most of the increased in-hospital charges.

Prior studies estimating the economic costs of coronary angioplasty have, in general, reviewed audited inhospital and 1-year total charges. ${ }^{12-15}$ However, the use of hospital charges as a substitute for true economic costs may have important limitations. ${ }^{20}$ In-hospital charges are often discounted by third-party payers, so that reimbursement may actually be less than the aver- age true economic cost of a service. ${ }^{15}$ To compensate for losses in one area, hospitals may "cost-shift," charging more than the true economic cost for other services that are more substantially reimbursed by third-party payers. $^{20}$

Hlatky et $\mathrm{al}^{21}$ used standard cost-accounting methods to relate direct costs plus allocated hospital overhead, an index of true economic cost, to hospital charges. In the 389 patients evaluated, direct costs plus allocated hospital overhead were 0.78 of hospital charges, not dissimilar from the estimated cost-charge ratio of 0.76 in the present study. Provided that hospital charges for each service would be discounted by the same cost/charge ratio -- an assumption that may be inaccurate in the event of "cost-shifting" - the results of the present study would suggest that intracoronary stent placement may require more than twice the im-

\begin{tabular}{|c|c|c|c|c|c|c|c|c|}
\hline \multirow[b]{2}{*}{ Study } & \multirow{2}{*}{$\begin{array}{l}\text { No. of } \\
\text { Vessels }\end{array}$} & \multirow{2}{*}{$\begin{array}{l}\text { No. of } \\
\text { Pts. }\end{array}$} & \multicolumn{2}{|c|}{ Hospital Days } & \multicolumn{2}{|c|}{ In-Hospital Charges (\$) } & \multirow[b]{2}{*}{ Ratio } & \multirow{2}{*}{$\begin{array}{l}\text { Follow-Up } \\
\text { Period }\end{array}$} \\
\hline & & & PTCA & CABG & PTCA & CABG & & \\
\hline Jang $(1984)^{11}$ & Single & 361 & $4 \pm 2$ & $12 \pm 5$ & $5,313 \pm 2,159$ & $15,580 \pm 2,159$ & 2.9 & In-hospital \\
\hline Reeder $(1984)^{12}$ & Single & 168 & 9.4 & 13.1 & 11,384 & 13,387 & 1.2 & 1 year \\
\hline Kelly $(1985)^{13}$ & Single & 112 & $5 \pm 4$ & $10 \pm 4$ & 7,689 & 13,559 & 1.8 & 1 year \\
\hline Black (1988) ${ }^{14}$ & Multi- & 200 & 5 & 13 & 9,138 & 22,771 & 2.5 & 1 year \\
\hline Barbash (1986) ${ }^{15}$ & Multi- & 52 & $6 \pm 5$ & - & $8,500 \pm 4,700$ & - & * & In-hospital \\
\hline Hlatky $(1990)^{21}$ & Single & 389 & $7 \pm 4$ & $14 \pm 6$ & $9,556 \pm 5,251$ & $19,644 \pm 9,157$ & 2.0 & In-hospital \\
\hline Present study & Multi- & 50 & $2 \pm 1$ & - & $6,220 \pm 5,176$ & - & * & In-hospital \\
\hline
\end{tabular}

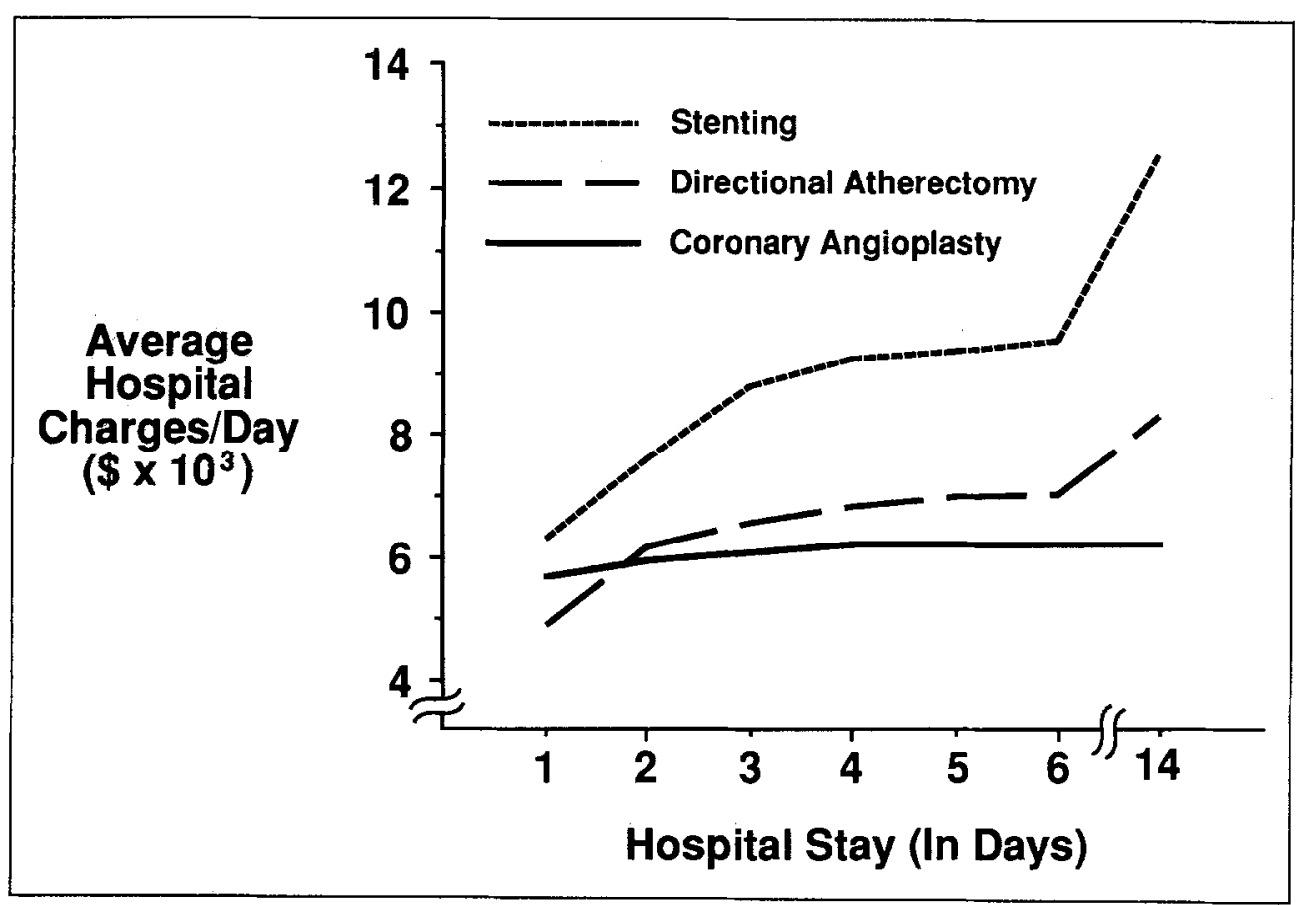

FIGURE 2. Average in-hospltal cumulative daily charges for patients undergoing nonsurgical revascularization. Patients undergoing intracoronary stenting had significantly higher in-hospital charges throughout the hospital period. 
mediate in-hospital economic resources as standard coronary angioplasty; directional coronary atherectomy may require nearly $40 \%$ more resources than coronary angioplasty.

Several factors influenced in-hospital charges for the 3 treatment strategies. The postprocedural in-hospital stay for patients undergoing balloon angioplasty $(2 \pm 1$ days) was substantially shorter than the in-hospital stay reported in prior studies (range 5 to 14 days) (Table IV). Furthermore, accounting for 1989 dollars, the inhospital charges for balloon angioplasty were also lower in the present report, reflecting the elective nature of the study population, the same day admission policy for coronary angioplasty, and more rapid hospital discharge with uncomplicated patients. As a result, the comparatively high in-hospital charges with directional atherectomy and intracoronary stent may simply reflect the evolution of lower in-hospital charges associated with coronary angioplasty. In fact, the 5-day hospital stay for patients with an intracoronary stent in the present study is not substantially different from the length of stay with historic cohorts of coronary angioplasty (Table IV). Vascular complications occurred more often in patients undergoing stent placement and directional atherectomy than in patients undergoing coronary angioplasty, often prolonging the hospitalization period. Whereas increased operator experience and modification in equipment design may reduce the noted vascular complication rate, the requirement for systemic anticoagulation in patients undergoing stent placement necessitates longer periods of in-hospital observation. Potentially, the development of nonthrombogenic stents will permit shorter periods of in-hospital observation in the future.

Admittedly, the present study examines only the immediate in-hospital charges associated with coronary angioplasty, directional atherectomy and intracoronary stenting. Estimation of the overall economic cost of these procedures would require inclusion of the subsequent "induced-costs" associated with late restenosis. ${ }^{22}$ In a previous study examining the economic costs associated with coronary angioplasty, restenosis was associated with $\$ 10,641$ of additional hospitalization charges, although the number of patients treated with coronary bypass surgery for restenosis was high. ${ }^{12}$ Despite multiple pharmacologic approaches aimed at its prevention, restenosis still develops in up to $40 \%$ of patients within the 3 to 6 months after coronary angioplasty. ${ }^{4} \mathrm{Al}-$ though it is hoped that restenosis will be lower using directional atherectomy and intracoronary stenting, it has been reported in patients undergoing these procedures. ${ }^{17,18} \mathrm{~A}$ definitive reduction in restenosis and associated induced-costs using these techniques will require randomized trials.
Several previous studies have compared hospital charges associated with coronary angioplasty and coronary bypass surgery (Table IV), convincingly demonstrating the potential economic savings of coronary angioplasty in patients with single ${ }^{11,12}$ and multivessel coronary artery disease. ${ }^{14,15,21}$ Whereas the duration of follow-up has varied in these different studies, the ratio of hospital charges associated with coronary bypass surgery to coronary angioplasty has ranged from 1.2 to 2.9. Notably, many patients undergoing intracoronary stent placement in the present study had unsuccessful coronary angioplasty 1 or more times. Before introduction of the intracoronary stent, these patients would have been candidates for coronary bypass surgery alone, and compared with surgical patients from these historic controls, the in-hospital days and hospital charges associated with intracoronary stent placement are still quite favorable.

The present study has several important limitations. First, these comparative data are derived from a nonrandomized study with new device use in a relatively early stage of development. Modifications in equipment design and operator technique may result in future reductions of in-hospital charges for these alternative devices. Second, as previously noted, the present study includes only immediate in-hospital charges, and does not include either charges associated with late restenosis, charges associated with the increased surveillance associated with intracoronary stents such as coagulation profile monitoring required during 2 to 3 months of anticoagulation, or the social impact of these devices on patient lifestyle and back-to-work status. Therefore, the long-term economic benefits of these devices may not be fully realized. Finally, the technique of coronary angioplasty is in constant evolution. Whereas patient selection criteria have broadened, hospitalization days have shortened and in-hospital charges have been lower. Similarly, the major source of increased in-hospital charges in patients undergoing intracoronary stent placement in the present study was a prolonged in-hospital stay, partially attributed to an increased bleeding complication rate and requirement for systemic anticoagulation associated with intracoronary stenting. Earlier sheath removal and alternative anticoagulation schemes, such as an adjusted subcutaneous dose of hep$\operatorname{arin}^{23}$ and bedside coagulation monitoring, and the development of nonthrombogenic intracoronary stents may substantially reduce the required hospitalization time in future studies.

\section{RIPIRENCES}

1. Gruentzig AR, Henning A, Siegenthaler WE. Nonoperative dilation of coronary artery stenosis: percutaneous transluminal coronary angioplasty. $N$ Engl $J$ Med 1979;301:61-68. 
2. Detre KM, Holmes DR, Holubkov R, Cowley MJ, Bourassa MG, Faxon DP, Dorros GR, Bentivoglio LG, Kent KM, Myler RK. Incidence and consequences of periprocedural occlusion. The 1985-1986 National Heart, Lung, and Blood Institute Percutaneous Transluminal Coronary Angioplasty Registry. Circulation 1990;82:739-750.

3. Ellis SG, Roubin GS, King SB, Douglas JS, Weintraub WS, Thomas RG, Cox WR. Angiographic and clinical predictors of acute closure after native vessel coronary angioplasty. Circulation 1988;72:372-379.

4. Popma JJ, Topol EJ. Factors influencing restenosis following coronary angioplasty. Am J Med 1990;88:1N-23N.

5. Schat $\angle$ RA, Baim DS, Leon M, Ellis SG, Goldbcrg S, Hirschficld JW, Clcman MW, Cabin HS, Walker C, Stagg J, Buchbinder M, Teirstein PS, Topol EJ, Savage M, Perez JA, Curry RC, Whitworth H, Sousa JE, Tio F, Almagor Y, Ponder R, Penn IM, Leonard B, Levine SL, Fish RD, Palmaz JC. Clinical experience with the Palmaz-Schatz coronary stent. Initial results of a multicenter study. Circulation 1991;83:148-161.

6. Roubin GS, King SB, Douglas JS, Lembo NJ, Robinson KA. Intracoronary stenting during percutaneous transluminal coronary angioplasty. Circulation 1990;81 (suppl IV):IV-92-IV-100.

7. Serruys PW, Strauss BH, Beatt KJ, Bertrand ME, Puel J, Rickards AF, Meier B, Goy J-J, Vogt P, Kappenberger L, Sigwart U. Angiographic follow-up after placement of a self-expanding coronary-artery stent. N Engl J Med 1991;324: 13-17.

8. Hinohara T, Selmon MR, Robertson GC, Braden L, Simpson JS. Directional atherectomy. New approaches for treatment of obstructive coronary and peripheral vascular disease. Circulation 1990;81(suppl IV):IV-79-IV-91.

9. Leon MB, Kent KM, Pichard AD, Satler LF. Coronary atherectomy: a clinical update. Coranary Artery Disease 1990;1:421-429

10. Karsch KR, Haase KK, Voelker W, Baumbach G, Mauser M, Seipel L. Percutaneous coronary excimer laser angioplasty in patients with stable and unstable angina pectoris: acute results and incidence of restenosis at 6-month follow-up. Circulation 1990;81:1849-1859.

11. Jang GC, Block PC, Cowley MJ, Gruentzig AR, Dorros G, Holmes DR Jr, Kent KM, Leatherman LL, Myler RK, Sjolander SME, Stertzer SII, Vetrovec GW, Willis WH, Williams DO. Relative cost of coronary angioplasty and bypass surgery in a one-vessel model. Am J Cardiol 1984;53:52C-55C.

12. Reeder GS, Krishan I, Nobrega FT, Naessens J, Kelly M, Christianson JB, McAfec MK. Is percutaneous coronary angioplasty less expensive than bypass surgery? $N$ Engl J Med 1984;311:1157-1162.

13. Kelly ME, Taylor GJ, Moses HW, Mikell FL, Dove JT, Batchelder JE, Wellons HA Jr, Schneider JA. Comparative cost of myocardial revascularization, percutaneous transluminal angioplasty and coronary artery bypass. $J$ Am Coll Cardiol 1985;5:16-20.

14. Black JR, Roubin GS, Sutor C, Moe N, Jarboe JM, Douglas JA Jr, King SB. Comparative costs of percutaneous transluminal coronary angioplasty and coronary artery bypass grafting in multivessel coronary artery disease. Am $J$ Cardiol 1989;62:809-811.

15. Barbash GI, Rabkin MT, Kane NM, Baim DS. Coronary angioplasty under the prospective payment system: the need for a severity-adjusted payment schemc. $J$ Am Coll Cardiol 1986;8:784-790.

16. Ryan TJ, Faxon DP, Gunnar RM, Kennedy JW, King SB, Loop FD, Peterson KL, Revves TJ, Williams DO, Winters WL. Guidelines for perculaneous transluminal coronary angioplasty. A report of the American College of Cardiology/American Heart Association Task Force on Assessment of Diagnostic and Therapeutic Cardjovascular Procedures (Subcommittee on Percutaneous Transluminal Coronary Angioplasty). J Am Coll Cardiol 1988;12:529-545.

17. Robinson GC, Hinohara T, Selmon MR, Johnson DE, Simpson JB. Directional Coronary Atherectomy. In: Topol EJ. Textbook of Interventional Cardiology. Philadelphia: WB Saunders, 1990:563-579.

18. Muller DWM, Ellis SG. Advances in coronary angioplasty: endovascular stents. Coronary Artery Disease 1990;1:438-448.

19. Muller DWM, Ellis SG, Debowey DL, Topol EJ. Quantitative angiographic comparison of the immediate success of coronary angioplasty, coronary atherectomy, and endoluminal stenting. Am I Cardiol 1990;66:938-942.

20. Finkler SA. The distinction between costs and charges. Ann Intern Med 1982;1:102-109.

21. Hlatky MA, Lipscomb J, Nelson C, Califf RM, Pryor D, Wallace AG, Mark DB. Resource use and cost of initial coronary revascularization. Coronary angioplasty versus coronary bypass surgery. Circulation 1990;82(suppl IV):IV-208IV-213.

22. Reeder GS. Angioplasty and the cost of myocardial revascularization: has the promisc bcen fulfillod? Int J Card Imaging 1987;15:287-292.

23. Turpie AGG, Robinson JG, Doyle DJ. Comparison of high-dose with lowdose subcutaneous heparin to prevent left ventricular thrombosis in patients with acute transmural anterior myocardial infarction. $N$ Engl $J$ Med 1989;320: $352-357$. 